Gut, 1988, 29, 1279-1281

\title{
Recurrent bleeding from cutaneous venous collaterals in portal hypertension
}

\author{
H R VAN BUUREN, T E FICK, AND S W SCHALM \\ From the Departments of Internal Medicine and Surgery, University Hospital Dijkzigt, Rotterdam, The \\ Netherlands
}

SUMMARY In portal hypertension, three types of cutaneous portosystemic collaterals may develop: the 'classical' caput Medusae, enterostomal varices and scar or adhesion-related abdominal collaterals. Two patients were treated with severe and recurrent bleeding from adhesion-related collaterals, a complication not reported previously. In the first patient bleeding was only controlled by mesocaval shunt operation; the second patient suffered no further recurrence after local sclerotherapy.

Portal hypertension is characterised by the development of splanchnic systemic venous connections that decompress the portal venous system. Although this is a protective adaptation, several pathological conditions, such as hepatic encephalopathy and pulmonary hypertension,' can be associated with the collateral blood flow. The most important is gastrointestinal haemorrhage, usually from oesophagogastric varices but occasionally from varices elsewhere in the intestinal or biliary tract. ${ }^{2}$ Moreover, intra-abdominal bleeding from peritoneal varices, ${ }^{3}$ external bleeding from stomal varices, ${ }^{4}$ and genitourinary variceal bleeding ${ }^{2}$ may occur. We report on two patients with severe and recurrent bleeding from cutaneous, scar related collaterals that developed after abdominal surgery. This is a complication which, to our knowledge, has not been previously described in the literature.

\section{PATIENT 1}

A 48 year old man with biopsy diagnosed alcoholic cirrhosis was admitted with bleeding from the abdominal wall which started as a result of scratching. Four years previously a sigmoid resection with construction of a stoma of the transverse colon was carried out because of perforation of the sigmoid

Address for correspondence: S W Schalm, Dept of Internal Medicine II, University Hospital Dijkzigt, Dr Molewaterplein 40, 3015 GD Rotterdam, The Netherlands.

Received for publication 8 April 1988. colon with abscess formation. The continuity of the colon was restored six months later.

On physical examination a caput Medusae like cutaneous venous pattern with a tiny bleeding spot was seen originating from a midline abdominal surgical scar. Local ligation was done but within two weeks three recurrent haemorrhages necessitated a local pressure bandage, transfusion of 5 units of blood and repeated local ligations. Again, bleeding recurred two weeks later. Because local therapy had failed, we decided that shunt surgery should be carried out. At surgery the umbilical vein in the falciform ligament was found to be still obliterated, but there were multiple adhesions with large venous collaterals between the omentum, intestines, and abdominal wall. A mesocaval interposition shunt was constructed. Bleeding did not recur; the patient died from hepatic insufficiency seven years later.

PATIENT 2

A 69 year old man was admitted to our department after two episodes of bleeding from the abdominal wall. Three years previously an exploratory laparotomy had been carried out elsewhere for jaundice and abdominal pain. A hilar cholangiocarcinoma was suspected; during the subsequent cholecystectomy, a T-drain was inserted through a stenosis of a proximal bile duct. Postoperative review of biopsies and cholangiograms led to a diagnosis of sclerosing cholangitis. The drain was left in situ because it was presumed to stent a major stricture of the left hepatic 


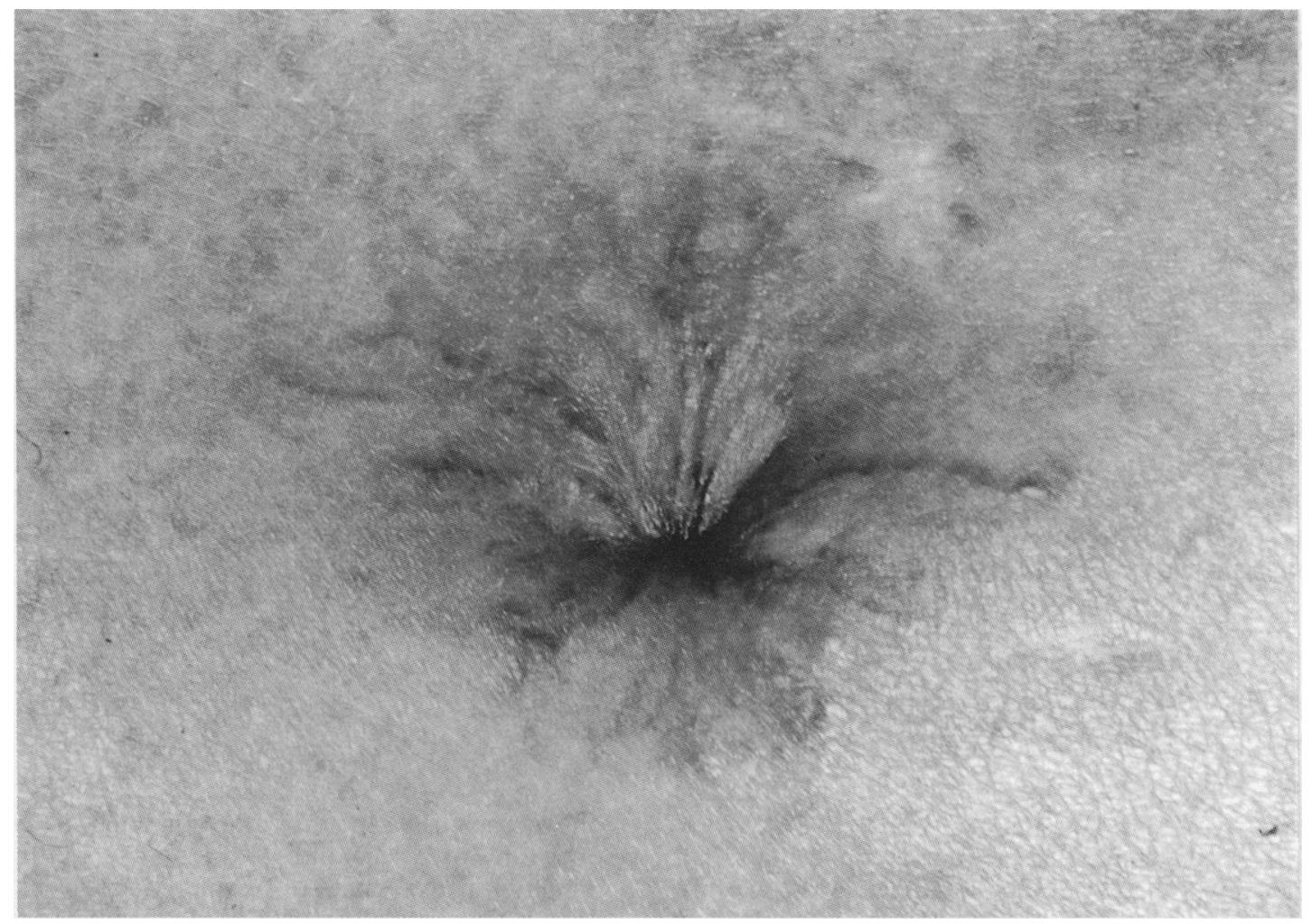

Figure Patient 2: small portosystemic collateral veins radiating from the T-drain orifice.

bile duct and later would allow intermittent lavage of the bile duct system. During the two years before admission several episodes of oesophageal variceal bleeding had occurred which were managed by endoscopic sclerotherapy. Examination of the abdominal skin revealed several small blue veins, surrounding and radiating from the $\mathrm{T}$-drain orifice.

A diagnosis of bleeding from portosystemic collateral cutaneous veins, possibly induced by mechanical friction of the drain, was made. Recurrent haemorrhage from the T-tube tract two months later required transfusion of 8 units of blood and led to removal of the T-drain (Figure). Two weeks later, another haemorrhage and the transfusion of 5 units of blood led to another therapeutic approach. The orifice and superficial part of the Tdrain tract were injected subcutaneously, at three different sites, with $4 \mathrm{ml}$ of $5 \%$ ethanolamine. Although the spider of small bluish vessels remained visible, bleeding did not recur during the following two years. The patient died from recurrent gastric variceal bleeding complicated by bacterial peritonitis.

\section{Discussion}

In portal hypertension cutaneous portosystemic collaterals may develop when pre-existing connections between the portal and systemic venous systems reopen or abdominal organs are brought in contact with the abdominal wall.

The classical type of cutaneous collateral is the caput Medusae, a relatively rare characteristic pattern of veins radiating from the umbilicus. The caput results from venous anastomoses between the portal and caval systems through the recanalised umbilical vein. Prominent veins near scars of previous laparotomies represent the second and more common type of cutaneous collateral. These vessels develop in postoperative adhesions, where anastomoses may form between the mesenteric venous network and veins of the abdominal wall. The resulting cutaneous vascular pattern may be much like a caput Medusae, as illustrated by the findings for our first patient. The bleeding cutaneous veins in our patients were of this adhesion related type.

The third and clinically most important cutaneous 
collaterals are varices that develop at the mucocutaneous junction of an enteral stoma in patients with portal hypertension. These stomal varices may cause severe and recurrent bleeding. Local therapy - for example, direct pressure, ligation of the varices or stomal revision, may be successful, ${ }^{5}$ but in some patients only shunt surgery will provide definitive control. ${ }^{6}$ In contrast with bleeding from stomal varices bleeding from a caput Medusae or scar related collaterals has never been described. In our patients the very rare event of bleeding from the latter condition may have been initiated by mechanical damage to the vessel wall (scratching, friction of the T-drain), although bleeding recurred without obvious trauma in both cases. Simple conservative treatment - local pressure and ligation - did not prevent renewed haemorrhage. Ultimately, only the construction of a mesocaval shunt provided longterm control in the first patient. The simple and more elegant approach of local sclerotherapy was effective in our second patient.

The success of this treatment is supported by several reports on the favourable results of injection sclerotherapy for stomal variceal bleeding. ${ }^{78} \mathrm{We}$ conclude that bleeding from cutaneous adhesionrelated portosystemic collateral veins is a rare but potentially serious event in patients with portal hypertension. Local sclerotherapy is advocated as the initial treatment. More invasive therapy, such as shunt surgery or vascular disconnection procedures, should be considered only if this approach fails.

\section{References}

1 Lebrec D, Capron JP, Dhumeaux D, Benhamou JP. Pulmonary hypertension complicating portal hypertension. Am Rev Respir Dis 1979; 120: 849-56.

2 Lebrec D, Benhamou JP. Ectopic varices in portal hypertension. Clinics Gastroenterol 1985; 14: 105-21.

3 Fox L, Crane SA, Bidari C, Jones A. Intra-abdominal hemorrhage from ruptured varices. Arch Surg 1982; 117: 953-5.

4 Wiesner RH, LaRusso NF, Dozois RR, Beaver SJ. Peristomal varices after proctocolectomy in patients with primary sclerosing cholangitis. Gastroenterology 1986; 90: $316-22$.

5 Grundfest-Broniatowski S, Fazio F. Conservative treatment of bleeding stomal varices. Arch Surg 1983; 118: 981-5.

6 Adson MA, Fulton RE. The ileal stoma and portal hypertension: an uncommon site of variceal bleeding. Arch Surg 1977; 112: 501-4.

7 Morgan TR, Feldshon SD, Tripp MR. Recurrent stomal variceal bleeding. Successful treatment using injection sclerotherapy. Dis Colon Rectum 1986; 29: 269-70.

8 Hesterberg R, Stahlknecht CD, Roher HD. Sclerotherapy for massive enterostomy bleeding resulting from portal hypertension. Dis Colon Rectum 1986; 29: 275-7. 